Abstract-Identification of the spatial scale at which marine communities are organized is critical to proper management, yet this is particularly difficult to determine for highly migratory species like sharks. We used shark catch data collected during 2006-09 from fishery-independent bottom-longline surveys, as well as biotic and abiotic explanatory data to identify the factors that affect the distribution of coastal sharks at 2 spatial scales in the northern Gulf of Mexico. Centered principal component analyses (PCAs) were used to visualize the patterns that characterize shark distributions at small (Alabama and Mississippi coast) and large (northern Gulf of Mexico) spatial scales. Environmental data on temperature, salinity, dissolved oxygen (DO), depth, fish and crustacean biomass, and chlorophyll- $a$ (chl- $a$ ) concentration were analyzed with normed PCAs at both spatial scales. The relationships between values of shark catch per unit of effort (CPUE) and environmental factors were then analyzed at each scale with co-inertia analysis (COIA). Results from COIA indicated that the degree of agreement between the structure of the environmental and shark data sets was relatively higher at the small spatial scale than at the large one. CPUE of Blacktip Shark (Carcharhinus limbatus) was related positively with crustacean biomass at both spatial scales. Similarly, CPUE of Atlantic Sharpnose Shark (Rhizoprionodon terraenovae) was related positively with chl- $a$ concentration and negatively with DO at both spatial scales. Conversely, distribution of Blacknose Shark (C. acronotus) displayed a contrasting relationship with depth at the 2 scales considered. Our results indicate that the factors influencing the distribution of sharks in the northern Gulf of Mexico are species specific but generally transcend the spatial boundaries used in our analyses.

Manuscript submitted 25 October 2012. Manuscript accepted 29 August 2013. Fish. Bull. 111:370-380.

doi: 10.7755/FB.111.4.6

The views and opinions expressed or implied in this article are those of the author (or authors) and do not necesarily reflect the position of the National Marine Fisheries Service, NOAA.

\title{
Multiscale analysis of factors that affect the distribution of sharks throughout the northern Gulf of Mexico
}

\author{
J. Marcus Drymon (contact author) ${ }^{1,2}$ \\ Laure Carassou ${ }^{3}$ \\ Sean P. Powers ${ }^{1,2}$ \\ Mark Grace ${ }^{4}$ \\ John Dindo² \\ Brian Dzwonkowski² \\ Email address for contact author: mdrymon@disl.org \\ ${ }^{1}$ Department of Marine Sciences \\ University of South Alabama, LSCB-25 \\ Mobile, Alabama 36688 \\ 2 Dauphin Island Sea Lab \\ 101 Bienville Boulevard \\ Dauphin Island, Alabama 36528 \\ 3 Department of Zoology and Entomology \\ Rhodes University \\ P.O. Box 94 \\ Grahamstown 6140, South Africa \\ ${ }^{4}$ Mississippi Laboratories \\ Southeast Fisheries Science Center \\ National Marine Fisheries Service, NOAA \\ 3209 Frederic Street \\ Pascagoula, Mississippi 39567
}

Paramount to the conservation of marine resources and ecosystems is the identification of proper spatial scales for management plans. Although long recognized as a central, if not universal, concept in ecology, the notion of scale more recently has begun a transition from qualitative description to quantitative assessment (Schneider, 2001). For marine systems, this transition is particularly important because choice of spatial scale directly affects the identification of patterns (Perry and Ommer, 2003). As fisheries management plans transition to an ecosystembased approach, the identification of suitable spatial scales becomes even more important (Hughes et al., 2005; Francis et al., 2007).

For sharks, many of which are considered top predators and play a central role in regulation of marine ecosystems (Heithaus et al., 2008), the identification of appropriate spatial scales for management is made more difficult than the identification of spatial scales for bony fishes because of their highly migratory nature and relative paucity. Traditional mark-and-recapture methods allow for examination of gross spatialscale patterns in sharks, but these methods are limited by low recapture rates. Pop-up satellite archival tags circumvent this problem by exponentially increasing the odds of retrieving data from tagged sharks. Unfortunately, their use is often cost prohibitive, and the algorithms presently employed to estimate geographic locations are too coarse to provide reliable spatial pattern data on small scales (i.e., tens of kilometers) (Sims, 2010; Hammerschlag et al., 2011). Consequently, information 

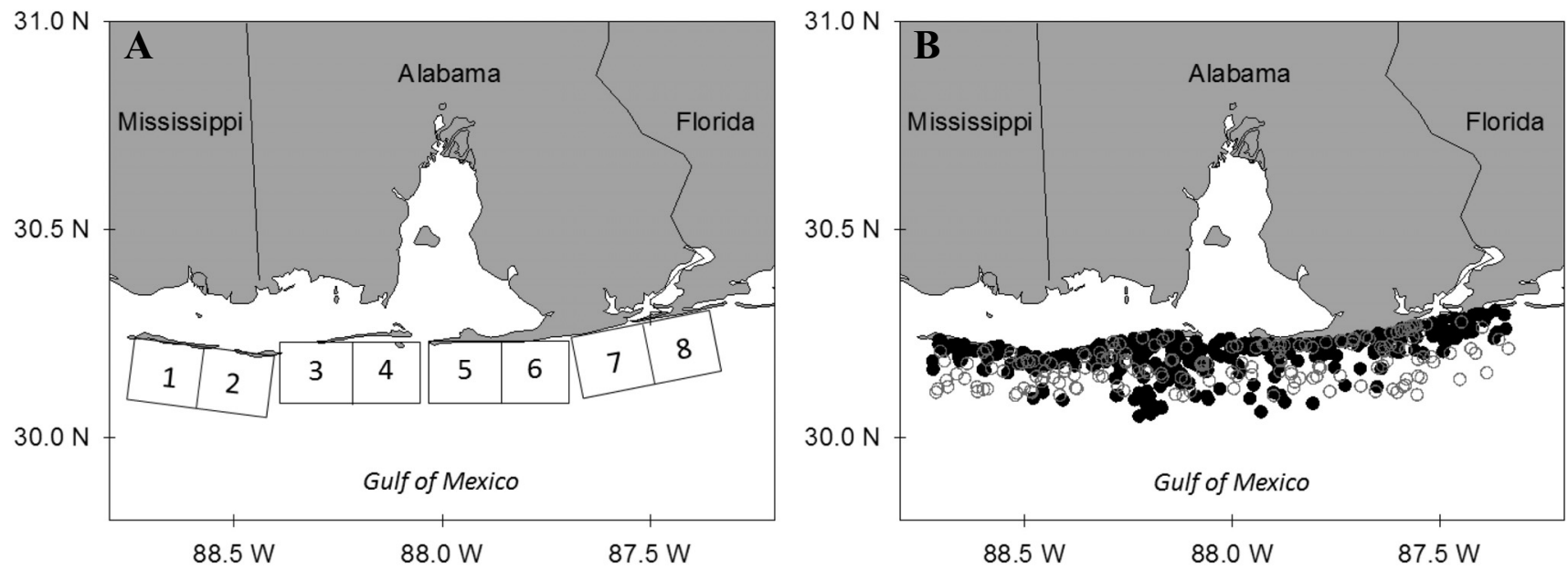

Figure 1

Spatial extent of the area used in our small-scale analysis of shark distribution in the northern Gulf of Mexico during 2006-09. (A) Eight blocks (1-8, west to east), which spanned depths from 1 to $\sim 20 \mathrm{~m}$, where the shark bottom-longline survey was conducted during all months by the Dauphin Island Sea Laboratory. (B) Sample locations for the smallscale bottom-longline data during 2006-09 (filled circles) and trawl data during 2007-09 from the Southeast Area Monitoring and Assessment Program database (http://seamap.gsmfc.org) (open circles).

concerning spatial patterns and distributions of shark communities in coastal marine systems is still needed before resource managers can successfully incorporate sharks into sustainable ecosystem management plans (Heithaus et al., 2007).

Long-term, fishery-independent monitoring programs are one of the most common ways to assess spatial patterns for marine vertebrates. The NOAA Southeast Fisheries Science Center (SEFSC) Mississippi Laboratories have been conducting annual bottomlongline surveys to assess patterns of shark distributions across the entire northern Gulf of Mexico since 1995, and the data from these surveys are incorporated into stock assessments that ultimately shape fishery management plans for these animals. Given the importance of merging biological scales with the scales of fisheries management, we sought to examine spatial patterns in assemblages of shark species on the scale of the northern Gulf of Mexico and to investigate to what extent those patterns in shark communities were present regionally, along the coasts of Mississippi and Alabama.

The goal of this investigation was to characterize the spatial distribution of shark communities in coastal waters of the northern Gulf of Mexico. Previous studies have examined the distributions of coastal sharks in the northern Gulf of Mexico (Drymon et al., 2010), and we sought to further the approach in these studies by relating spatial trends in shark species assemblages to abiotic and biotic data, including the degree to which these patterns were driven by the availability of potential prey items. Ultimately, we wanted to determine whether patterns in the structure of shark communities and the factors that drive them are independent of scale. We predict this multifaceted approach will allow for a more precise understanding of the determinants of the spatial distributions of these predators in nature and for a definition of appropriate management measures.

\section{Materials and methods}

\section{Small-scale study site}

A bottom-longline survey was initiated in May 2006 by the National Marine Fisheries Service (NMFS) and the Dauphin Island Sea Lab (DISL). During this survey sharks were sampled from waters at depths of 1-20 m along the Alabama and Mississippi coastlines (Fig.1). Sampling occurred during all months (January-December) on NMFS research vessels (all 20-30 m in length), such as the RV HST, RV Gandy, and RV Caretta. A stratified random block design was used and 8 blocks were established along the combined coast of Mississippi and Alabama. Each block was $\sim 10 \mathrm{~km}$ east-west and extended from the shoreline to approximately the $20-\mathrm{m}$ isobath. Blocks 1-4 were located west of $88^{\circ} 00 \mathrm{~W}$ (western blocks), and blocks 5-8 were located east of $88^{\circ} 00 \mathrm{~W}$ (eastern blocks) (Fig. 1A). Sampling was allocated evenly and replicated within each block. For this study, we analyzed data collected in 2006-09 as part of this survey.

\section{Small-scale sampling methods}

Between 12 and 16 stations were randomly selected and sampled each month using a stratified random 

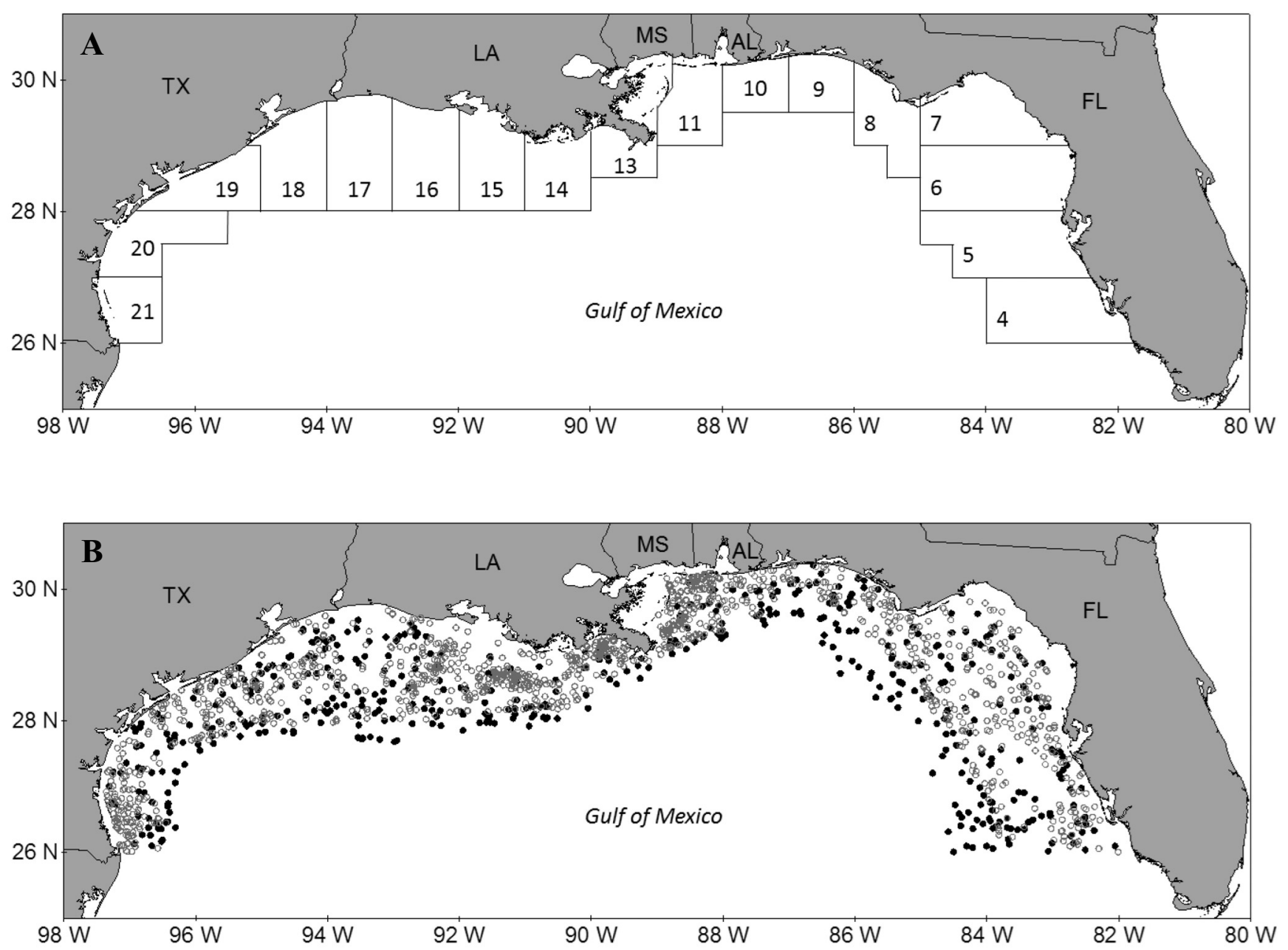

Figure 2

Spatial extent of the area used in the large-scale analysis of shark distribution in the northern Gulf of Mexico during 2006-09. (A) Seventeen National Marine Fisheries Service statistical zones (4-21 east to west, excluding zone 12), which spanned depths from 1 to $\sim 250 \mathrm{~m}$, where the bottom-longline sets were conducted by the NOAA Southeast Fisheries Science Center Mississippi Laboratories during the months of August and September. (B) Sampling locations for the large-scale bottom-longline data for 2006-09 are indicated by filled circles; trawl data for 2007-09 from the Southeast Area Monitoring and Assessment Program database (http://seamap.gsmfc.org) are indicated by open circles.

survey design that ensured equal effort across blocks $1-8$ and the range of depths sampled (Fig. 1A). At each station, a single bottom-longline was set and soaked for $1 \mathrm{~h}$. The main line consisted of $1.85 \mathrm{~km}(1 \mathrm{nmi})$ of 4-mm monofilament (545-kg test) that was set with 100 gangions. Gangions consisted of a longline snap and a 15/0 circle hook baited with Atlantic Mackerel (Scomber scombrus). Each gangion was made of $3.66 \mathrm{~m}$ of 3-mm monofilament (320-kg test).

Sharks that could be boated safely were removed from the main line, unhooked, and identified to species following Castro (2011). For each individual, sex, length (precaudal, fork, natural, and stretch total in centimeters), weight (in kilograms), and maturity stage (when possible) were recorded. All length measurements originated at the tip of the rostrum and terminated at the origin of the precaudal pit, the noticeable fork in the tail, the upper lobe of the caudal fin in a natural position, and the upper lobe of the caudal fin in a stretched position for precaudal, fork, natural, and stretch total lengths, respectively. Maturity in males was assessed according to Clark and von Schmidt (1965). Sharks were tagged either on the anterior dorsal fin with a plastic Rototag ${ }^{1}$ (Dalton ID, Henley-onThames, UK) or just below the first dorsal fin with a metal dart tag. Which tag type was used depended both

\footnotetext{
${ }^{1}$ Mention of tradenames or commercial companies is for identification purposes only and does not imply endorsement by the National Marine Fisheries Service, NOAA.
} 
on species and size of a shark at capture (Kohler and Turner, 2001).

\section{Additional data sets}

To determine whether the patterns that characterize the shark community assemblage in our study region (coasts of Alabama and Mississippi, hereafter referred to as small scale) were applicable across the northern Gulf of Mexico (hereafter called large scale), we obtained bottom-longline data from the SEFSC Mississippi Laboratories. This information included catch, fork length, and environmental data collected across Gulf of Mexico statistical zones 4-21 (Fig. 2A) in 2006-09. During that period bottom-longline sets were conducted by the Mississippi Laboratories in August and September. The methods used for the bottom-longline survey were identical at the small and large scales, and a complete description of these methods is provided in Driggers et al. (2008).

To examine factors that potentially influence the distribution of sharks on both small and large scales, we analyzed the relationships between longline shark data and a set of environmental factors, including trawl data and abiotic parameters. Biotic trawl data were obtained from the Southeast Area Monitoring and Assessment Program (SEAMAP) database (http://seamap. gsmfc.org, November 2010) of the Gulf States Marine Fisheries Commission. We restricted our analysis of SEAMAP data to those years for which trawling was conducted across the entire northern Gulf of Mexico (2007-09). The data from those years that were used in our analysis originated from both state (Louisiana, Alabama, Mississippi, and Florida) and federal (NOAA Fisheries) regulatory agencies. All data archived in the SEAMAP trawl database were collected according to standard SEAMAP trawl protocols (Rester, 2012). Two biotic variables, representative of the availability of potential prey for sharks, were selected for inclusion in our analysis of SEAMAP trawl data: fish biomass and crustacean biomass per station in kilograms. All biomass data from the trawl data set were standardized to kilogram per minute. The abiotic variables temperature (degrees Celsius), salinity (practical salinity unit), dissolved oxygen (milligrams per liter) and depth (meters) were collected with conductivity, temperature, and depth (CTD) instruments (SBE 911plus and SBE 25plus Sealogger, Sea-Bird Electronics, Inc., Bellevue, WA) during bottom-longline sampling at both the large and small scales.

To include a proxy for primary production in our analysis, we used data on chlorophyll- $a$ (chl- $a$ ) concentration as a measure of phytoplankton biomass (Canion, 2008; Martinez-Lopez and Zavala-Hidalgo, 2009). The satellite-based ocean color data used in this study were derived from the moderate resolution imaging spectroradiometer (MODIS) on the Aqua satellite (for a detailed sensor description go to the MODIS mission website at http://modis.gsfc.nasa.gov). The data on chl- $a$ concentration used for analyses in our study were downloaded from the Ocean Color website (http:// oceancolor.gsfc.nasa.gov, accessed April 2012). For this study, annual binned level-3 chl- $a$ data (Campbell et al., 1995) at a spatial resolution of $4 \mathrm{~km}$ were used from 2006 to 2009. The annual composites are produced by averaging all valid, cloud-free acquisitions for each ocean pixel. The valid pixels are determined by using an extensive quality control process that tests for numerous factors known to degrade data accuracy. Additional details for the level-3 chl- $a$ data can be found at http://modis.gsfc.nasa.gov/data/atbd/index.php. Despite that extensive quality control process, the optically complex nature of the coastal zone can still present difficulties for ocean color algorithms. In the case of data on chl- $a$ concentration, algorithms are known to overestimate concentrations in coastal zones, particularly in regions that are influenced by a river, because of estuarine materials, such as suspended sediment and concentrations of dissolved organic material. However, this phenomenon occurs primarily at depths $<10 \mathrm{~m}$ (Martinez-Lopez and Zavala-Hidalgo, 2009); therefore, we obtained data on chl- $a$ concentration from the $25-\mathrm{m}$ isobath to limit the effect of these degrading influences.

\section{Data analyses}

Bottom-longline data sets were limited to those species observed in both the small- and large-scale bottom-longline surveys. Data of catch per unit of effort (CPUE), measured as sharks 100 hooks $^{-1} \mathrm{~h}^{-1}$, were $\log (x+1)$-transformed to reduce the influence of the most common species and to standardize the data (Legendre and Legendre, 1998). All sets, including those with zero catches, were included in our analyses. Mean CPUE data were then analyzed as a function of block (blocks 1-8) across the small scale (Fig. 1A) and as a function of statistical zone (zones 4-21, minus zone 12) across the large scale (Fig. 2A).

A centered principal component analysis (PCA) was performed on mean transformed shark CPUE data for both small- and large-scale data. The data collected with the CTD instruments and the MODIS satellite data (collectively hereafter referred to as environmental data) at both small and large scales were analyzed with a normed PCA. At each spatial scale, centered (for shark CPUE data) and normed (for environmental data) PCAs allowed for the identification of the major spatial patterns that characterize shark assemblages and environmental conditions and for the visualization of covariances between shark species and of correlations between environmental factors (Legendre and Legendre, 1998).

The relationships between values of shark CPUE and environmental factors were then analyzed at each spatial scale with co-inertia analyses (COIA). Co-inertia analysis is a flexible, multivariate method that couples environmental and faunal data and measures the degree of agreement between them (Dolédec and 
Chessel, 1994; Dray et al., 2003). This method has been used successfully on diverse ecological data sets and organisms, including fishes (e.g., Mellin et al., 2007; Carassou et al., 2011; Lecchini et al., 2012), zooplankton (e.g., Carassou et al., 2010), benthic invertebrates (e.g., Bremner et al., 2003), and bacteria (e.g., Jardillier et al., 2004). In our study, each COIA was based on the matching of a normed PCA of environmental data and a centered PCA of shark abundance data (PCAPCA-COIA, Dray et al., 2003). Monte Carlo tests with 10,000 permutations between observations were used to confirm the significance of COIA results (fixed-D test; Dray et al., 2003), with significance assessed at $P \leq 0.05$. For each COIA, the vectorial correlation (RV) coefficient, a multivariate generalization of the squared Pearson's correlation coefficient, provided a quantitative measure of the co-structure between explanative (environmental) and explained (shark CPUE) variables, with a value of 1 indicating a perfect match between the 2 data sets (Dolédec and Chessel, 1994; Dray et al., 2003). The criterion of total inertia was used to compare the amount of agreement between environmental and shark data for the 2 spatial scales considered (Dray et al., 2003). All multivariate analyses were performed with the ADE-4 software (Thioulouse et al., 1997, 1995-2000).

\section{Results}

\section{Small-scale sampling}

During small-scale sampling, 353 stations were surveyed, spanning the months from March to November during 2006-09 (Fig. 1B). Winter months (December, January, and February) were excluded from subsequent analyses because of the complete absence of sharks in the small-scale survey area during this time $(2100$ hooks with no sharks). Over the course of this survey, 2417 individuals representing 12 shark species were encountered. Of these 12 species, 5 species met our criteria for inclusion in subsequent analyses (i.e., they also were abundant in the large-scale data set): Atlantic Sharpnose Shark (Rhizoprionodon terraenovae), Blacktip Shark (Carcharhinus limbatus), Blacknose Shark (C. acronotus), Spinner Shark (C. brevipinna), and Bull Shark (C. leucas). Mean CPUE ( \pm standard error [SE]) ranged from 2.88 [0.28] sharks 100 hooks $^{-1} \mathrm{~h}^{-1}$ for Atlantic Sharpnose Shark to 0.11 (0.02) sharks 100 hooks ${ }^{-1} \mathrm{~h}^{-1}$ for Bull Shark (Table 1). Wide size ranges, with size measured as fork length (FL) in centimeters, were found for Atlantic Sharpnose (36.0-96.3 cm FL), Blacktip (59.8-164.0 cm FL), Blacknose (40.9-136.0 cm FL), and Spinner (49.9-165.9 cm FL) Sharks. A smaller size range was seen for Bull Sharks (73.0-155.5 cm $\mathrm{FL}$ ), the least commonly encountered of the 5 species (Table 1).

The centered PCA conducted with small-scale data on shark abundance explained $91.88 \%$ of the variabil- ity between observations (across blocks 1-8) on the first 2 principal components (PC1 and PC2) (Fig. 3A). Variation along PC1 was explained primarily by data for Atlantic Sharpnose Shark, which was most abundant in blocks 2,3 , and 4 (western blocks), less common in block 1, and relatively rare in blocks $5,6,7$, and 8 (eastern blocks). Spinner Shark showed a similar but less marked spatial pattern (Fig. 3A). Variation along PC2 was explained primarily by data for Blacktip Shark, which was more abundant in block 1 (western block), and relatively rare in block 5 and 6 (eastern blocks) (Fig. 3A). Patterns were less clear for Blacknose and Bull Shark.

The normed PCA on small-scale environmental data explained $74.18 \%$ of the variability between observations (blocks) on the first 2 principle components (PC1 and PC2) (Fig. 4A). Temperature and crustacean biomass were positively correlated with each other and both of those variables had a high negative correlation with salinity. These 3 variables explained most of the variability along PC1. Fish biomass was negatively correlated with depth. Chl- $a$ concentration and dissolved oxygen were negatively correlated, together explaining most of the variability along PC2. Blocks 7 and 8 (eastern blocks) were characterized by high dissolved oxygen and low concentration of chl- $a$, and the inverse was true for block 3 (a western block) (Fig. 4A).

The COIA that coupled small-scale shark abundance and environmental data was characterized by a total inertia of 0.22 and an RV coefficient of 0.65 , indicating a relatively high degree of agreement between the structures of the 2 data sets. Axes 1 and 2 supported 99.17\% of this common structure (Fig. 5A). Atlantic Sharpnose Shark abundance was positively related with chl- $a$ concentration and negatively related with dissolved oxygen and salinity. Abundance of Blacktip Shark was more positively associated with crustacean biomass than with other environmental variables. Blacknose and Spinner Sharks had high negative associations with dissolved oxygen, and Blacknose Shark had a strong positive association with depth (Fig. 5A).

\section{Large-scale sampling}

Across the large-scale survey area, shark abundance data were obtained from 551 stations sampled during the months of August and September during 2006-09 (Fig. 2B). Over the course of this survey, 4493 sharks, comprising 26 species, were captured. Mean catch per unit of effort $( \pm \mathrm{SE})$ ranged from $4.74(0.41)$ sharks 100 hooks $^{-1} \mathrm{~h}^{-1}$ for Atlantic Sharpnose Shark to 0.06 (0.01) sharks 100 hooks $^{-1} \mathrm{~h}^{-1}$ for Bull Shark (Table 1). Wide size ranges were observed for Atlantic Sharpnose (33.0-115.5 cm FL), Blacktip (38.2-157.0 cm FL), Blacknose (40.0-104.9 cm FL), and Spinner (54.0-169.0 cm FL) Sharks. The smallest size range was seen in Bull Shark (131.4-176.0 cm FL), the least commonly encountered of the 5 species (Table 1 ). 
Table 1

Data that we used in our analyses of shark distribution in the northern Gulf of Mexico during 2006-09. Number, mean size (measured as fork length [FL] in centimeters and standard error of the mean [SE]), size range, and mean catch per unit of effort (CPUE), measured as sharks 100 hooks ${ }^{-1} \mathrm{~h}^{-1}$, are shown for the 5 shark species common to both of the 2 data sets: small (Alabama and Mississippi coasts) and large (across the northern Gulf of Mexico). The 5 species were Atlantic Sharpnose Shark (Rhizoprionodon terraenovae), Blacktip Shark (Carcharhinus limbatus), Blacknose Shark (C. acronotus), Spinner Shark (C. brevipinna), and Bull Shark (C. leucas). $n=$ no. of sharks sampled.

\begin{tabular}{|c|c|c|c|c|}
\hline Species & $n$ & $\begin{array}{c}\text { Mean size } \\
\pm \mathrm{SE}(\mathrm{cm} \mathrm{FL})\end{array}$ & $\begin{array}{l}\text { Range } \\
\text { (cm FL) }\end{array}$ & $\begin{array}{c}\text { Mean CPUE } \\
\pm \mathrm{SE}\left(\text { sharks } 100 \text { hooks }^{-1} \mathrm{~h}^{-1}\right)\end{array}$ \\
\hline \multicolumn{5}{|l|}{ Small scale } \\
\hline Atlantic Sharpnose Shark & 1016 & $68.8(0.43)$ & $36.0-96.3$ & $2.88(0.28)$ \\
\hline Blacktip Shark & 474 & $102.7(0.93)$ & $59.8-164.0$ & $1.34(0.14)$ \\
\hline Blacknose Shark & 600 & $91.1(0.42)$ & $40.9-136.0$ & $1.70(0.19)$ \\
\hline Spinner Shark & 147 & $70.1(1.86)$ & $49.9-165.9$ & $0.42(0.06)$ \\
\hline Bull Shark & 40 & $102.8(6.09)$ & $73.0-155.5$ & $0.11(0.02)$ \\
\hline \multicolumn{5}{|l|}{ Large scale } \\
\hline Atlantic Sharpnose Shark & 2596 & $73.9(0.20)$ & $33.0-115.5$ & $4.74(0.41)$ \\
\hline Blacktip Shark & 254 & $111.7(1.19)$ & $38.2-157.0$ & $0.51(0.08)$ \\
\hline Blacknose Shark & 530 & $85.0(0.52)$ & $40.0-104.9$ & $0.98(0.11)$ \\
\hline Spinner Shark & 158 & $104.7(2.17)$ & $54.0-169.0$ & $0.29(0.08)$ \\
\hline Bull Shark & 21 & $155.0(2.77)$ & $131.4-176.0$ & $0.06(0.01)$ \\
\hline
\end{tabular}

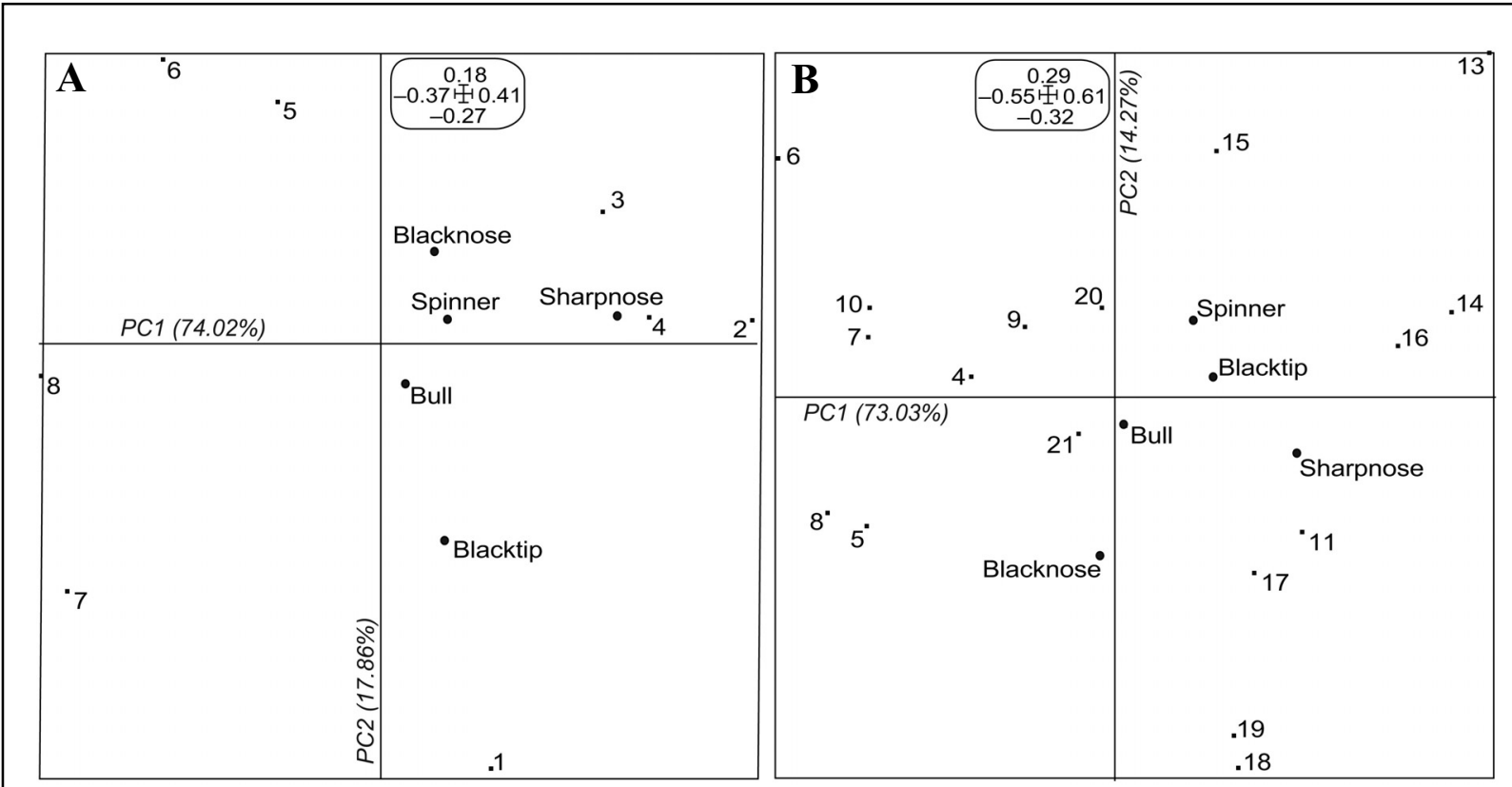

Figure 3

Results of the centered principal components analysis (PCA) on shark data from (A) small-scale and (B) largescale bottom-longline surveys conducted in the northern Gulf of Mexico during 2006-09. Numbers within the panels correspond to the sampling blocks (1-8) and statistical zones (4-21, minus 12) of the small- and largescale surveys, respectively, used in our analysis (blocks and zones are defined in Figs. 1 and 2). Filled circles represent shark species. The sum of the variation explained by the first (PC1) and second (PC2) principal components is $91.88 \%$ for small-scale survey and $87.30 \%$ for large-scale survey. The scale is shown in ovals at top of each panel. 


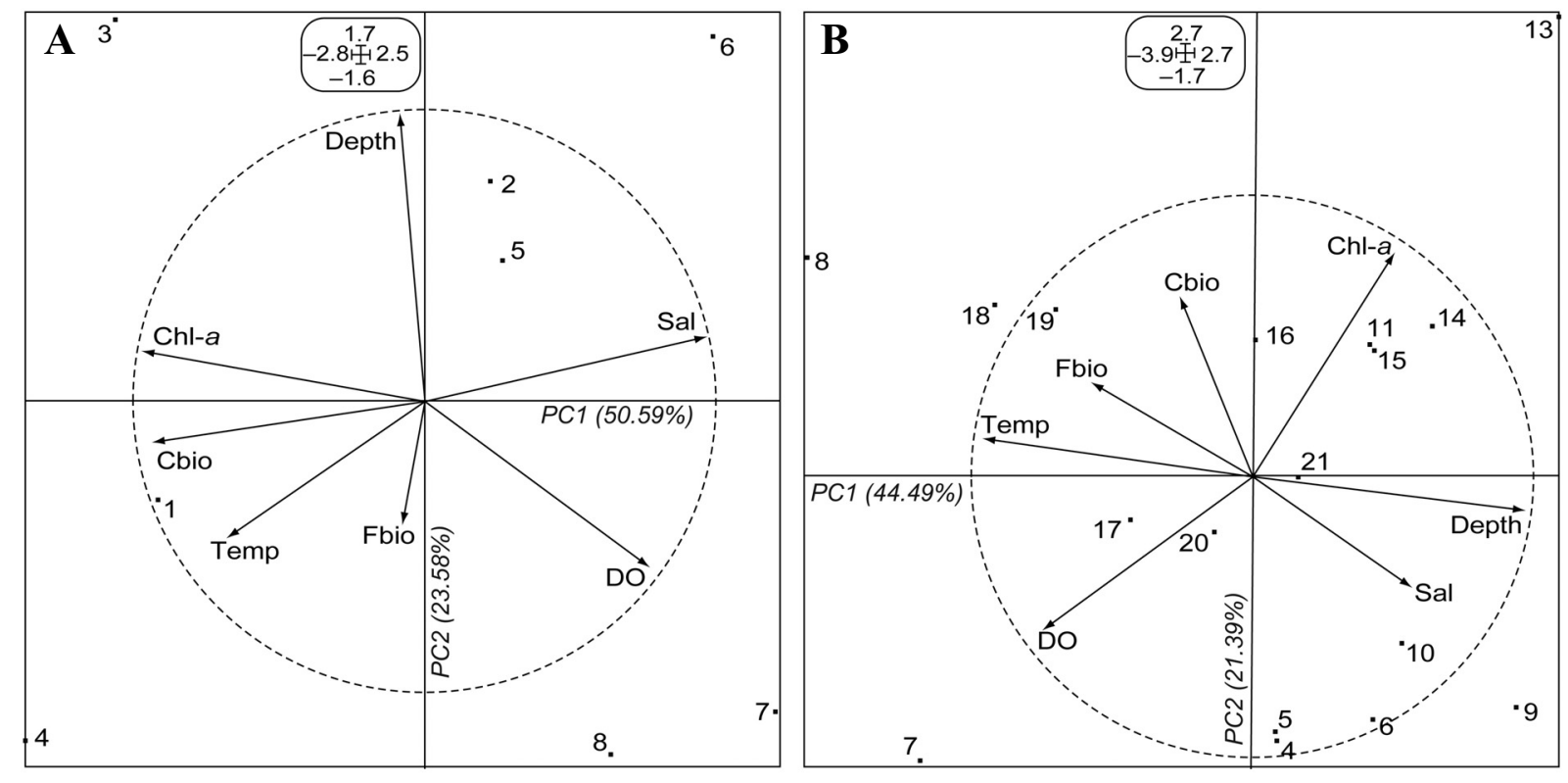

Figure 4

Results of the normed principal components analysis (PCA) on (A) small- and (B) large-scale environmental data from CTD casts conducted during the bottom-longline survey in the northern Gulf of Mexico during 2006-09, trawl data from the Southeast Area Monitoring and Assessment Program database (http://seamap.gsmfc.org) for 20072009, and from the moderate resolution imaging spectroradiometer on the Aqua satellite (http://modis.gsfc.nasa.gov) for 2006-2009. Numbers within the panel correspond to the sampling blocks (1-8) and statistical zones (4-21, minus 12) of the small- and large-scale surveys, respectively, used in our analysis (blocks and zones are defined in Figures 1 and 2). Arrows represent abiotic variables, and dashed-line circles represent correlation circles with a unit of 1. Variation explained by the first (PC1) and second (PC2) principal components is $74.18 \%$ for the small-scale survey and $65.88 \%$ for the large-scale survey. The scale is shown in ovals at top of each panel. Cbio=crustacean biomass, Chl- $a=$ chlorophyll- $a$, DO=dissolved oxygen, Fbio=fish biomass, Sal=salinity, Temp=temperature.

The centered PCA conducted with large-scale data on shark abundance explained $87.30 \%$ of the variability between observations (across NMFS statistical zones) on the first 2 principal components (Fig. 3B). Variation along PC1 was mainly explained by data for Atlantic Sharpnose Shark, which was more abundant in zones 11, 14, and 16 (western zones), and variation along PC2 was mainly explained by data for Blacknose Shark, which was more abundant in zones 3 and 5 (eastern zones) (Fig. 3B). Compared with other species, Bull Shark displayed a weaker pattern because of their lower abundances (Fig. 3B).

The normed PCA on large-scale environmental data explained $65.88 \%$ of the variability between observations (NMFS statistical zones) on the first 2 principle components (Fig. 4B). Fish biomass and temperature were correlated, and both of these variables were negatively correlated with depth. These 3 variables explained most of the variability along PC1 (Fig. 4B). Chl- $a$ concentration and crustacean biomass were positively correlated, and concentration of chl- $a$ had a strong negative correlation with dissolved oxygen. Together, these 3 variables explained the majority of vari- ability along PC2. NMFS statistical zones 11, 14, 15, and 16 were characterized by high chl- $a$ concentration, and zones 18 and 19 were characterized by high fish biomass. Conversely, eastern zones $4-6$ were characterized by low fish and crustacean biomass (Fig. 4B).

The COIA that coupled large-scale shark abundance and environmental data was characterized by a total inertia of 0.20 and a RV coefficient of 0.42 , indicating good agreement between the 2 data sets. Axes 1 and 2 supported $97.32 \%$ of this common structure (Fig. 5B). Abundance of Atlantic Sharpnose Shark was strongly related to chl- $a$ concentration and had a strong negative relation to dissolved oxygen. Spinner Shark showed a similar pattern. Blacktip Shark abundance was related to crustacean biomass and had a strong negative relation to salinity. Abundance of Blacknose Shark was strongly related to temperature and inversely related to depth (Fig. 5B)

\section{Discussion}

For comparison of the factors that affect the distribution of sharks across spatial scales, COIA provides a 

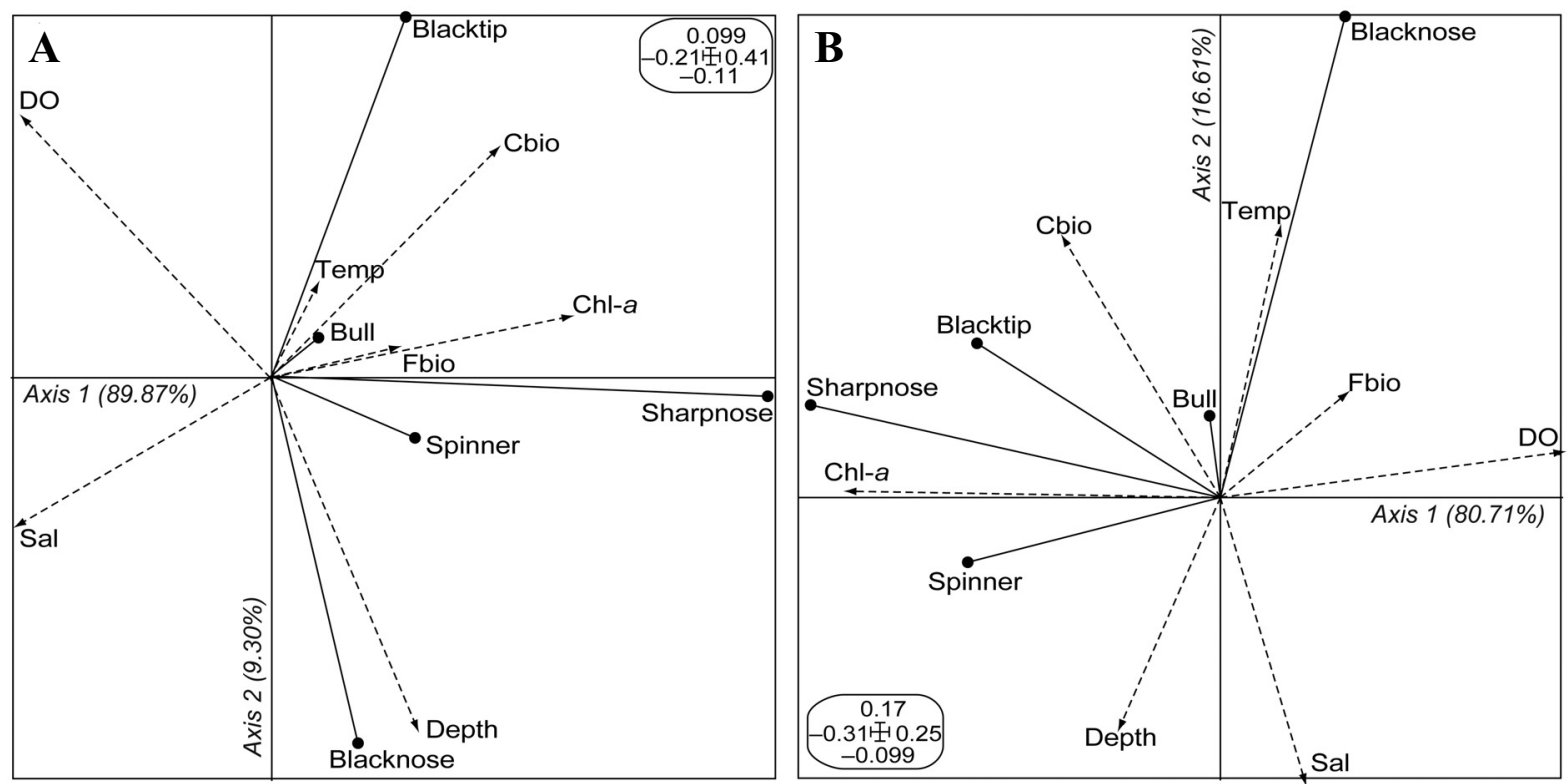

Figure 5

Results of the co-inertia analyses on (A) small- and (B) large-scale shark and environmental data from the northern Gulf of Mexico during 2006-09. Small-scale total inertia is 0.22, and axes 1 and 2 supported 99.17\% of this structure. Large-scale total inertia is 0.20 , and axes 1 and 2 supported $97.32 \%$ of this structure. The scale is shown in ovals at top of each panel. Arrows and dotted lines represent environmental variables. Filled circles and full lines represent shark species. Cbio=crustacean biomass, Chl- $a=$ chlorophyll $-a, \mathrm{DO}=$ dissolved oxygen, Fbio=fish biomass, Sal=salinity, Temp=temperature.

robust tool. Examination of the results for total inertia indicates that analyses at both small and large scales were equally useful for identification of patterns between sharks and explanatory variables. However, the RV coefficients indicate that explanatory variables were better correlated with shark abundances at the small scale $(R V=0.65)$ than at the large scale $(R V=0.42)$. Given 1) the unique coupling of bottom-longline data sets collected through the use of identical methods across the same temporal scale and 2) the similarity in shark size and catch between the surveys at 2 spatial scales, our data are particularly well suited to COIA. Our results indicate that the factors affecting the distribution of sharks in the Gulf of Mexico are species specific but relatively well conserved across spatial scales.

The factors that affect the distribution of Blacktip Shark were similar at small and large scales, and the distribution of this species was best explained by crustacean biomass at both scales. However, it is unlikely that Blacktip Shark responded to crustaceans as potential prey. Although previous studies of feeding habits of Blacktip Shark in the northern Gulf of Mexico (Hoffmayer and Parsons, 2003; Barry et al., 2008) and Florida (Heupel and Hueter, 2002) have identified crustacean components, these same studies have revealed that Blacktip Sharks prey predominately on teleosts. That Blacktip Shark distributions may not be influ- enced by the distribution of their preferred prey is not surprising. In an acoustic telemetry study in Terra Ceia Bay, Florida, no correlation was found between juvenile Blacktip Shark and their prey (Heupel and Hueter, 2002). After examination of the influence of prey abundance on the distribution of sharks (including Blacktip Shark) at 2 spatial scales, Torres et al. (2006) showed no correlation between shark catch and teleost abundance at individual sampling locations, although a correlation was shown between shark catch and teleost abundance within a region. The strong relationship observed in our study between Blacktip Shark and crustacean biomass at both spatial scales indicates that perhaps the underlying mechanism that most influences the distribution of this species correlates with crustacean biomass.

Distribution of Atlantic Sharpnose Shark was best explained by chl- $a$ concentration, a pattern that, like the one seen for Blacktip Shark, was independent of scale. However, although Blacktip Shark may have been influenced by factors other than prey, Atlantic Sharpnose Shark may have been indirectly responding to available prey as indicated by the observed relationship with concentration of chl- $a$. The contrast between Blacktip Shark and Atlantic Sharpnose Shark may illustrate basic differences in the ecology of these 2 species. As adults, Blacktip Sharks are a larger, more mo- 
bile species than Atlantic Sharpnose Sharks, and they are capable of moving hundreds of kilometers on short time scales, as illustrated by traditional (Kohler et al., 1998) and pop-up satellite archival (senior author and S. Powers, unpubl. data) tagging data. In contrast, Atlantic Sharpnose Sharks have a relatively small home range (Carlson et al., 2008). Blacktip Sharks, compared with Atlantic Sharpnose Sharks, may show higher vagility when faced with a patchy prey environment. For example, Atlantic Sharpnose Sharks sampled in the small-scale survey showed relative trophic plasticity. Portunid crabs and shrimp contribute more to the diet of Atlantic Sharpnose Sharks sampled west (blocks 1-4 in the current study) than to the diet of this shark species east (blocks 5-8) of Mobile Bay, and therefore may reflect differences in the prey base between these 2 areas (Drymon et al., 2012). These findings indicate that the Atlantic Sharpnose Shark may have a wider dietary breadth than the Blacktip Shark and may, therefore, be responding to gradients in overall production as opposed to fish or crustacean biomass, specifically.

Distributions of Atlantic Sharpnose and Spinner Sharks at both large and small scales were negatively related to dissolved oxygen. This relationship has been previously identified for other species of juvenile sharks. In Chesapeake Bay, Virginia, tree-based regression models indicated the importance of dissolved oxygen as a factor that influences the distribution of juvenile Sandbar Shark (Carcharhinus plumbeus) (Grubbs and Musick, 2007). Similarly, researchers have noted that, although dissolved oxygen is not as widely considered as temperature or salinity, it may play an important role as an environmental influence that affects the distribution of top predators in coastal environments, as has been demonstrated for juvenile Bull Shark in Florida waters (Heithaus et al., 2009).

In our study, a wide size range of Spinner Shark was documented across both the small- and large-scale surveys. On the basis of age and growth data (Carlson and Baremore, 2005), the mean sizes of Spinner Shark captured in small- and large-scale surveys corresponded to the ages of approximately 1 and 4 years old, respectively. Conversely, across surveys at both spatial scales, the mean size of Atlantic Sharpnose Shark was indicative of mature, adult animals (Carlson and Baremore, 2003). Our findings, therefore, support previous work that indicated the importance of dissolved oxygen as an influence on the distribution of juvenile sharks (Grubbs and Musick, 2007; Heithaus et al., 2009) and indicates that dissolved oxygen may influence the distribution of adult sharks as well.

Distributions of Blacknose Shark were best explained by depth, the direction of which varied as a function of scale. On the small scale, Blacknose Shark distribution was strongly and positively associated with water depth (i.e., deeper water resulted in higher Blacknose Shark CPUE). Conversely, at the large scale, distribution of Blacknose Shark were strongly and negatively associated with deep water (i.e., the shallower the depth, the lower the observed CPUE Blacknose Shark). This apparent dichotomy highlights differences in the range of depths associated with each spatial scale and likely reflects a preferred depth range for this species. Small-scale sampling occurred at depths up to $\sim 20 \mathrm{~m}$, and large-scale sampling occurred primarily at depths $>20 \mathrm{~m}$. Discrete depth preferences for Blacknose Shark have previously been documented. Analyzing the same 2 bottom-longline data sets used in our analyses, Drymon et al. (2010) showed a discrete depth preference of 10-30 m for Blacknose Shark. Our data support these findings yet provide no additional insight into why Blacknose Shark occupy these depths.

Although our analyses identified factors that may influence the distribution of selected shark species at 2 different spatial scales, our approach has certain limitations. For instance, the faunal component of our analyses was based on catch data (CPUE). Bait loss can affect CPUE calculations (Torres et al., 2006). In areas where (or during times when) bait loss is high, CPUE may be artificially low. Recording the status of individual gangions (i.e., fish caught, bait present, bait absent) allows for hook-specific CPUE to be calculated, resulting in more accurate determination of CPUE and, hence, improving the power of this approach. In addition, the analyses we used are sensitive to the temporal alignment of the data sets used. Restriction of analyses to data collected with the same methods and during the same time period will facilitate the identification of reliable relationships between faunal and explanatory data.

\section{Conclusions}

Identification of the factors that affect the distribution of large predators is challenging. Our analysis encompasses physical parameters (salinity, temperature, dissolved oxygen, and depth), proxies for primary (chl- $a$ concentration) and secondary (trawl) productivity, and predatory data sets across 2 spatial scales. Our results indicate that the factors that affect the distribution of sharks in the Gulf of Mexico are species dependent but may transcend the spatial boundaries that we examined. As physical and biological characteristics of ecosystems in the Gulf of Mexico change, species-specific knowledge of how these factors influence the distributions of top predators will be critical for the implementation of proactive management measures.

\section{Acknowledgments}

The authors wish to thank all members of the Fisheries Ecology Laboratory at Dauphin Island Sea Laboratory (DISL), as well as members of the NOAA Southeast Fisheries Science Center Mississippi Laboratories shark team for the countless hours they spent at sea collecting valuable data. Data from DISL's Fisheries 
Oceanography of Coastal Alabama research program, which is funded by the Alabama Department of Conservation and Natural Resources, Marine Resources Division, were used to provide ground truth for remotely sensed data from NASA's Sea-viewing Wide Field-ofview Sensor (SeaWifs) Project. We wish to thank T. Henwood and E. Hoffmayer from the National Marine Fisheries Service for constructive comments that improved this manuscript.

\section{Literature cited}

Barry, K. P., R. E. Condrey, W. B. Driggers III, and C. M. Jones. 2008. Feeding ecology and growth of neonate and juvenile blacktip sharks Carcharhinus limbatus in the Timbalier-Terrebone Bay complex, LA, U.S.A. J. Fish Biol. 73:650-662.

Bremner, J., S. I. Rogers, and C. L. J. Frid.

2003. Assessing functional diversity in marine benthic ecosystems: a comparison of approaches. Mar. Ecol. Prog. Ser. 254:11-25.

Campbell, J. W., J. M. Blaisdell, and M. Darzi.

1995. Level-3 SeaWiFS data products: spatial and temporal binning algorithms. NASA Tech. Memo. 104566, vol. $32,73 \mathrm{p}$.

Canion, A.K.

2008. Variability in productivity model inputs on multiple timescales: implications for productivity monitoring in Weeks Bay, Alabama. M.S. thesis, 99 p. Univ. South Alabama, Mobile, AL.

Carassou, L., R. LeBorgne, E. Rolland, and D. Ponton.

2010. Spatial and temporal distribution of zooplankton related to the environmental conditions in the coral reef lagoon of New Caledonia, Southwest Pacific. Mar. Pollut. Bull. 61:367-374.

Carassou, L., B. Dzwonkowski, F. J. Hernandez, S. P. Powers,

K. Park, W. M. Graham, and J. Mareska.

2011. Environmental influences on juvenile fish abundances in a river-dominated coastal system. Mar. Coast. Fish. 3:411-427.

Carlson, J. K., and I. E. Baremore.

2003. Changes in biological parameters of Atlantic sharpnose shark Rhizoprionodon terraenovae in the Gulf of Mexico: evidence for density-dependent growth and maturity? Mar. Freshw. Res. 54:227-234.

Carlson, J. K., and I. E. Baremore.

2005. Growth dynamics of the spinner shark (Carcharhinus brevipinna) off the United States southeast and Gulf of Mexico coasts: a comparison of methods. Fish. Bull. 103:280-291.

Carlson, J. K., M. R. Heupel, D. M. Bethea, and L. D. Hollensead.

2008. Coastal habitat use and residency of juvenile Atlantic sharpnose sharks (Rhizoprionodon terraenovae). Estuaries Coasts 31:931-940.

Castro, J. I.

2011. The sharks of North America, 640 p. Oxford Univ. Press, Inc., New York.

Clark, E., and K. von Schmidt.

1965. Sharks of the central Gulf coast of Florida. Bull. Mar. Sci. 15:13-83.
Dolédec, S., and D. Chessel.

1994. Co-inertia analysis: an alternative method for studying species-environment relationships. Freshw. Biol. 31:277-294.

Dray, S. D., D. Chessel, and J. Thioulouse.

2003. Co-inertia analysis and the linking of ecological data tables. Ecology 84(11):3078-3089.

Driggers, W. B., G. W. Ingram, M. A. Grace, C. T. Gledhill, T. A. Henwood, C. N. Horton, and C. M. Jones.

2008. Pupping areas and mortality rates of young tiger sharks Galeocerdo cuvier in the western North Atlantic Ocean. Aquat. Biol. 2:161-170.

Drymon, J. M., S. P. Powers, J. Dindo, B. Dzwonkowski, and T. A. Henwood.

2010. Distributions of sharks across a continental shelf in the northern Gulf of Mexico. Mar. Coast. Fish. 2:440-250.

Drymon, J. M., S. P. Powers, and R. H. Carmichael.

2012. Trophic plasticity in the Atlantic sharpnose shark (Rhizoprionodon terraenovae) from the north central Gulf of Mexico. Environ. Biol. Fishes 95:21-35.

Francis, R. C., M. A. Hixon, M. E. Clarke, S. A. Murawski, and S. Ralston.

2007. Ten commandments for ecosystem-based fisheries scientists. Fisheries 32:217-233.

Grubbs, R. D., and J. A. Musick.

2007. Spatial delineation of summer nursery areas for juvenile sandbar sharks in Chesapeake Bay, Virginia. Am. Fish. Soc. Symp. 50:87-108.

Hammerschlag, N., A. J. Gallagher, and D. M. Lazarre.

2011. A review of shark satellite tagging studies. J. Exp. Mar. Biol. Ecol. 398(1-2):1-8.

Heithaus, M. R., D. Burkholder, R. E. Heuter, L. I. Heithaus, H. R. Pratt Jr., and J. C. Carrier.

2007. Spatial and temporal variation in shark communities of the lower Florida Keys and evidence for historical population declines. Can. J. Fish. Aquat. Sci. 64:1302-1313.

Heithaus, M. R., A. Frid, A.J. Wirsing, and B. Worm.

2008. Predicting ecological consequences of marine top predator declines. Trends Ecol. Evol. 23:202-210.

Heithaus, M. R., B. K. Delius, A. J. Wirsing, and M. M. Dunphy-Daly.

2009. Physical factors influencing the distribution of a top predator in a subtropical oligotrophic estuary. Limnol. Oceanogr. 54:472-482.

Heupel, M. R., and R. E. Hueter.

2002. Importance of prey density in relation to the movement patterns of juvenile blacktip sharks (Carcharhinus limbatus) within a coastal nursery area. Mar. Freshw. Res. 53:543-550.

Hoffmayer, E. R., and G. R. Parsons.

2003. Food habits of three shark species from the Mississippi Sound in the northern Gulf of Mexico. Southeast. Nat. 2:271-280.

Hughes, T. P., D. R. Bellwood, C. Folke, R. S. Steneck, and J. Wilson.

2005. New paradigms for supporting the resilience of marine ecosystems. Trends Ecol. Evol. 20:380-386.

Jardillier, L., M. Basset, I. Domaizon, A. Belan, C. Amblard, M. Richardot, and D. Debroas.

2004. Bottom-up and top-down control of bacterial community composition in the euphotic zone of a reservoir. Aquat. Microb. Ecol. 35:259-273. 
Kohler, N. E., J. G. Casey, and P. A. Turner.

1998. NMFS cooperative shark tagging program, 19621993: an atlas of shark tag and recapture data. Mar. Fish. Rev. 60(2):1-87.

Kohler, N. E., and P. A. Turner.

2001. Shark tagging: a review of conventional methods and studies. Environ. Biol. Fishes. 60:191-223.

Lecchini, D., L. Carassou, B. Frédérich, Y. Nakamura, S. C. Mills, and R. Galzin.

2012. Effects of alternate reef states on coral reef fish habitat associations. Environ. Biol. Fishes 94:421-429.

Legendre, P., and L. Legendre.

1998. Numerical ecology, 2nd ed., 853 p. Elsevier Science, Amsterdam.

Martinez-Lopez, B., and J. Zavala-Hidalgo.

2009. Seasonal and interannual variability of cross-shelf transport of chlorophyll in the Gulf of Mexico. J. Mar. Syst.77:1-20.

Mellin, C., M. Kulbicki, and D. Ponton.

2007. Seasonal and ontogenetic patterns of habitat use in coral reef fish juveniles. Estuar. Coast. Shelf Sci. 75:481-491.

Perry, R. I., and R. E. Ommer.

2003. Scale issues in marine ecosystems and human interactions. Fish. Oceanogr. 12:513-522.
Schneider, D. C.

2001. The rise of the concept of scale in ecology. Bioscience 51:545-553.

Sims, D. W.

2010. Tracking and analysis techniques for understanding free-ranging shark movements and behavior. In Sharks and their relatives II: biodiversity, adaptive physiology, and conservation (J. C. Carrier, J. A. Musick, and M. R. Heithaus, eds.), p. 351-392. CRC Press, Boca Raton, FL.

Rester, J. K. (ed.).

2012. SEAMAP environmental and biological atlas of the Gulf of Mexico, 2010, 84 p. Gulf States Marine Fisheries Commission, Ocean Springs, MS.

Thioulouse, J., D. Chessel, S. Dolédec, and J-M. Olivier. 1997. ADE-4: a multivariate analysis and graphical display software. Stat. Comput. 7:75-83.

Thioulouse, J., D. Chessel, S. Dolédec, J-M. Oliver, F. Goreaud, and R. Pelissier.

1995-2000. ADE-4. Ecological data analysis: exploratory and euclidean methods in environmental sciences. Version 2001, CNRS, Lyon, France. [Available from http://pbil.univ-lyon1.fr/ADE-4-old/ADE-4.html.]

Torres, L. G., M. R. Heithaus, and B. Delius.

2006. Influence of teleost abundance on the distribution and abundance of sharks in Florida Bay, USA. Hydrobiologia 569:449-455. 